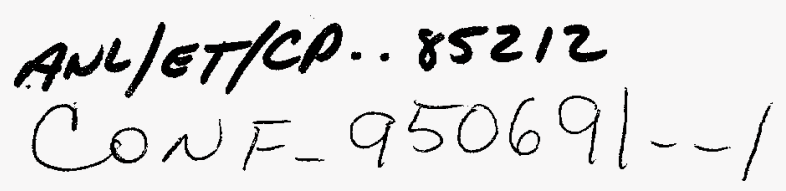

\title{
A Permanent-Magnet Rotor for a High-Temperature Superconducting Bearing
}

\author{
Thomas. M. Mulcahy, John. R. Hull*, and Kenneth. L. Uherka \\ Energy Technology, Argonne National Laboratory, Argonne, IL. 60439 \\ Robert G. Abboud \\ Commonwealth Research Corporation, Chicago, IL 60690 \\ James H. Wise and David W. Carnegie \\ UGIMAG, Valparaiso, IN 46383
}

Charles E. Bakis and Christopher W. Gabrys

Engineering Science, Pennsylvania State University, University Park, PA 16802

\begin{abstract}
Design, fabrication, and performance, of a 1/3-m dia., 10-kg flywheel rotor with only one bearing is discussed. To achieve low-loss energy storage, the rotor's segmented-ring permanentmagnet (PM) is optimized for levitation and circumferential homogeneity. The magnet's carbon composite bands enable practical energy storage.
\end{abstract}

\section{INTRODUCTION}

Sustainable superconductivity in the bulk form of hightemperature-superconductor (HTS) material enables the familiar demonstration of passive magnetic levitation and low-loss rotation of PMs, which, in turn, suggests its use as a bearing for long-term flywheel energy storage. However, commercial viability of the concept demands [1] that the low losses only recently realized with small, low-speed, singlepiece magnets [2], [3] be achieved for 2 to $5000-\mathrm{kWh}$ units that are limited in size only by truck-transport restrictions. To develop HTS bearings for likely utility-size MWh units, present manufacturing and material limitations indicate the stator consists of an assembly of individual HTSs and the rotor includes an assembly of PM pieces that can sustain uncommonly large inertia loading.

From a scale-up effort to $1 \mathrm{kWh}$, we describe a high-speed, multi-piece rotor with only one HTS bearing that has been measured to have acceptable losses at low speeds.

\section{The Rotor Permanent Magnet}

As in the familiar demonstrations, the rotor's HTS bearing uses only one PM: a double-ring assembly, with a vertical magnetic axis, is incorporated in a hoop-wound fibercomposite disk rotor that spins in a horizontal plane, as shown in Fig. 1. This concept was chosen because passive stabilization of a rotor's position, due to the stator HTSs' pinning of the magnet's flux, is greatest for this simplest of configurations: designs that incorporate additional PM bearings or PM elements in the stator, to enhance levitation, also add destabilizing forces and/or overturning moments that must be countered by the same HTS pinning. The single PM bearing design requires a larger PM and more HTSs to achieve

Manuscript received June 13,1995. Work partially supported by the U.S. Department of Energy, Energy Efficiency and Renewable Energy, as part of a program to develop electric power technology, under Contract W-31109-Eng-38.

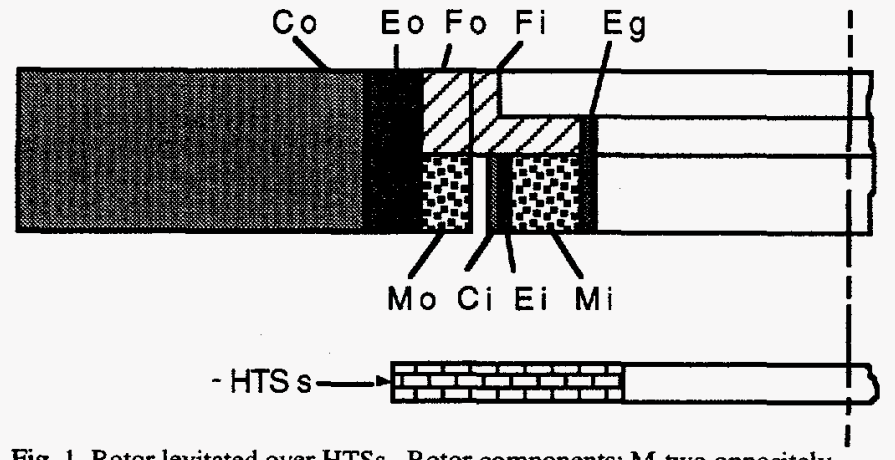

Fig. 1. Rotor levitated over HTSs. Rotor components: M-two oppositely magnetized magnet rings, F-iron rings, C-carbon bands, E-glass bands

the same levitation as designs augmented with additional PMs, but it is being pursued as one way to minimize high speed bearing losses and rotor dynamic resonances and instabilities: self centering is more achievable with a single bearing and more HTSs provide greater passive stabilization and motion damping.

The magnetic design of the double-ring PM was chosen to achieve high levitation forces for a given amount of PM material. The use of two concentric ring PMs of opposite polarity and equal volume is suggested by knowing [4] larger levitation forces occur for greater vertical PM field gradients at the HTS locations, assuming a constant magnetization density in the HTSs. Also, larger magnetic (levitation) pressures occur when larger horizontal field components exist between the ring PM and the HTSs. To minimize PM selfdemagnetization, the magnetic circuit between the tops of the PM rings is completed with a silicon-iron ring that has just enough thickness $(0.0064 \mathrm{~m})$ to avoid magnetic saturation. Since a priori calculation of the forces between PMs and HTSs is not yet possible, the radial spacing between the rings, Mo and $\mathrm{Mi}$, was chosen to maximize the repulsion force calculated between two such rotor PMs oriented in mirror-image opposition. The same calculations support the use of two concentric ring PMs of opposite polarity, instead of two with the same polarity or a single ring PM.

The 0.01254-m thick outside and inside PM rings, Mo and $\mathrm{Mi}$, were made from eight $45^{\circ}$ and six $60^{\circ}$ arc segments, respectively. The NdFeB material used (Ugimag $34 \mathrm{~K}$ ) was chosen for both its large residual induction (1.2T) and intrinsic coercive force $(1512 \mathrm{kA} / \mathrm{m})$. The magnet segments were cut with high precision from very uniformly oriented 


\section{DISCLAIMER}

This report was prepared as an account of work sponsored by an agency of the United States Government. Neither the United States Government nor any agency thereof, nor any of their employees, makes any warranty, express or implied, or assumes any legal liability or responsibility for the accuracy, completeness, or usefulness of any information, apparatus, product, or process disclosed, or represents that its use would not infringe privately owned rights. Reference herein to any specific commercial product, process, or service by trade name, trademark, manufacturer, or otherwise does not necessarily constitute or imply its endorsement, recommendation, or favoring by the United States Government or any agency thereof. The views and opinions of authors expressed herein do not necessarily state or reflect those of the United States Government or any agency thereof. 


\section{DISCLAIMER}

Portions of this document may be illegible in electronic image products. Images are produced from the best available original document. 


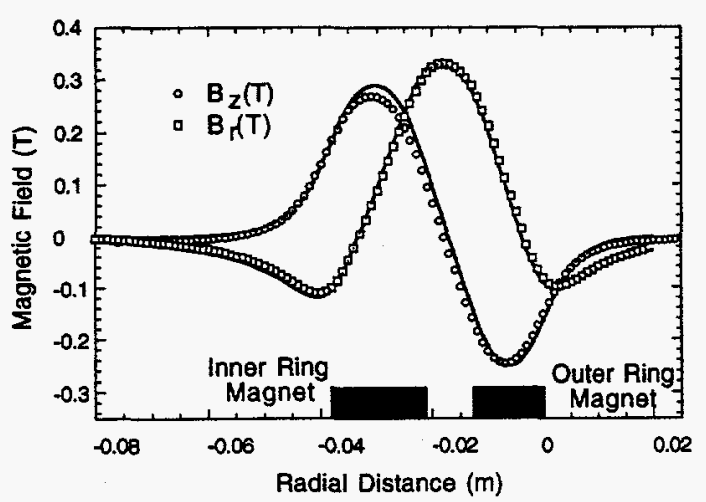

Fig. 2. Good correlation was found between measured (symbols) and predicted (lines) magnetic fields at $0.006 \mathrm{~m}$ below the rotor magnet.

blocks, made for fabrication of wiggler PM elements that required magnetic-moment tilts of less than $\pm 2^{\circ}$ and total moments within $\pm 2 \%$. To make the outer PM ring, Mo+Fo, PM segments were glued together and onto the silicon-iron ring Fo, in a special jig that minimized the air gaps at the seams. The inner $\mathrm{PM}$ ring, $(\mathrm{Mi}+\mathrm{Fi})$, was made in the same way. To maximize concentricity between the PM rings, the $\mathrm{OD}$ and the ID of each ring were ground and the two rings were fit (slight interference) together and pinned. A special press was built to overcome the $2500 \mathrm{~N}$ initial repulsion and smaller attraction that occurred between the magnets during assembly.

After assembly, the magnetic field below the rotor magnet was measured and compared to predictions made with available electromagnetic codes. The results of Fig. 2 are typical.

\section{MAGNET BANDING \\ A. Rotor Design}

The magnetic bearing's double-ring PM assembly is to be spun at maximum possible speed. However, the ring PMs need to be reinforced to remain intact at high speeds, because of their small tensile strength: see Table I. The use of highstrength hoop-wound composite bands to reinforce the PMs becomes essential and is possible, because the PMs' compressive strength is large. The composites' low density coupled with their relatively high stiffness minimizes their own radial growth under the centrifugal loading while their high strength allows generation of significant banding pressures on the PMs. Table I gives measured properties.

The banding of the inner and outer PM ringss was designed to employ press-fit assemblies instead of winding directly on the PMs for three reasons: (1) accurate prediction of the banding pressure generated from direct winding is difficult; (2) direct winding requires over heating of the PM for cure of the composite; and (3) direct winding is unlikely to achieve the high interference pressures capable from using press-fits.

The design procedure used superimposed anisotropic elasticity solutions [5], [6] that included rotational loading, internal and external pressures, and residual stresses from fabrication and temperature loading. The interference pressures between each ring were found by satisfying displacement and stress compatibility of the rings in the assembled flywheel. The pressures between the rings were used to check the
TABLE I MECHANICAL PROPERTIES

\begin{tabular}{|c|c|c|c|}
\hline Material & PM & Glass & Carbon \\
\hline Density $\left(\mathrm{Kg} / \mathrm{m}^{3}\right)$ & 7500 & 2085 & 1554 \\
\hline Hoop Modulus $\left(10^{9} \mathrm{~Pa}\right)$ & 170 & 61 & 158 \\
\hline Radial Modulus $\left(10^{9} \mathrm{~Pa}\right)$ & 170 & 18 & 9 \\
\hline Poisson's Ratio & 0.3 & 0.28 & 0.3 \\
\hline $\begin{array}{r}\text { Hoop Strength }\left(10^{6} \mathrm{~Pa}\right) \text {-tension } \\
\text {-compression }\end{array}$ & $\begin{array}{l}80 \\
-1103\end{array}$ & $\begin{array}{l}2303 \\
-206\end{array}$ & $\begin{array}{l}2648 \\
-318\end{array}$ \\
\hline $\begin{array}{r}\text { Radial Strength }\left(10^{6} \mathrm{~Pa}\right) \text {-tension } \\
\text {-compression }\end{array}$ & $\begin{array}{l}80 \\
-1103\end{array}$ & $\begin{array}{l}35 \\
-147\end{array}$ & $\begin{array}{l}40 \\
-153\end{array}$ \\
\hline
\end{tabular}

stresses in the rings at assembly, cooled to $-50^{\circ} \mathrm{C}$, and then spinning at $-50^{\circ} \mathrm{C}$. The maximum operating-speed criteria was that positive hoop stresses could not develop at the ID of either PM, signifying that the PM segments could develop gaps. The limiting factor in this design was the radial strength of the composite bands, which set an upper limit on the allowable banding pressures at about $150 \mathrm{MPa}$.

The maximum rotational speeds before formation of gaps in the inner and outer magnet segments are both approximately $2100 \mathrm{rad} / \mathrm{sec}(20 \mathrm{krpm})$. If operation can continue after gaps have developed in between the magnet segments, the maximum speed predicted before radial failure of the composite bands is $4160 \mathrm{rad} / \mathrm{sec}(39.7 \mathrm{krpm})$. See Table II for rotor dimensions and interference pressures. Note that the decrease in most of the interference pressures when cooled and spun is primarily due to the cooling, since spinning tends to increase the interference pressures.

\section{B. Rotor Fabrication}

All of the composite rings were fabricated using the in-situ curing, wet filament winding process [7]. In that process, the epoxy matrix is continually gelled as winding progresses, resulting in no fiber waviness, low void content, and low residual stresses. For the PM banding application, all fibers were wound in the hoop direction. The fibers used were Hercules AS4c carbon and Owens Corning 463 S2 glass. The matrix was Shell Epon $9405 / 9470$ epoxy and the final composites had a fiber volume fraction of approximately $70 \%$ with less than $2 \%$ porosity. The carbon rings were wound on tapered mandrels and the ODs of the glass bands were machined to the same tapers.

The press fitting operations were done by coating the mating surfaces with epoxy and partially sliding the rings together. Jigs were manufactured especially for the purpose of introducing loads at the proper locations on the assembly. A universal testing machine was used to press the rings together, while the epoxy was allowed to cure. Predictions of the necessary axial forces to complete the inner and outer press fits were 62 and $98 \mathrm{KN}$, respectively. A room temperature cure epoxy was used to prevent the need for heating of the magnet assemblies during the press fitting operation. The taper angle was chosen such that the shear stress in the epoxy bond was below its shear strength (14 $\mathrm{MPa}$ ) and that there was an approximately $50 \%$ overlap between rings prior to the application of the pressing force. 
TABLE II ROTOR DIMENSIONS AND INTERFERENCE PRESSURES

\begin{tabular}{llllll}
\hline Ring & Ri $(\mathrm{m})$ & Ro $(\mathrm{m})$ & Taper Angle & $\mathrm{P}(\mathrm{MPa})^{\mathrm{a}}$ & $\mathrm{P}(\mathrm{MPa})^{\mathrm{b}}$ \\
\hline $\mathrm{Eg}$ & .055563 & .061862 & none & 8 & 2 \\
$\mathrm{Mi}$ & .061923 & .080264 & none & 43 & 49 \\
$\mathrm{Ei}$ & .080315 & .084800 & $7^{\circ}$ on OD & 48 & 53 \\
$\mathrm{Ci}$ & .084000 & .087600 & $7^{\circ}$ on ID & & \\
$\mathrm{Mo}$ & .088900 & .101600 & none & 53 & 45 \\
$\mathrm{Eo}$ & .101651 & .120650 & $3^{\circ}$ on OD & 74 & 67 \\
$\mathrm{Co}$ & .120050 & .196850 & $3^{\circ}$ on ID & & \\
$\mathrm{Eo}$ & .101651 & .120650 & $3^{\circ}$ on OD & 99 & 43 \\
$\mathrm{~F}$ & .061923 & .101600 & none & 99 \\
\hline \multicolumn{5}{c}{$\mathrm{T}=21^{\circ} \mathrm{C} \mathrm{\&} \omega=0 \mathrm{rad} / \mathrm{s}$} & \multicolumn{5}{c}{$\mathrm{T}=-50^{\circ} \mathrm{C} \& \omega=2100 \mathrm{rad} / \mathrm{s}$}
\end{tabular}

\section{LOSSES}

Even in the familiar demonstrations that use imperfectly magnetized disk-shaped PMs magnets rotating over any HTS, the losses are observed to be small. When single-piece PMs rings are made to minimize circumferential inhomogeneity of the magnetic properties, the torque that resist axially rotation are so small that they must be measured indirectly. Typically, spin-down tests are performed, where the deceleration rates $\mathrm{d} f(\mathrm{~Hz}) / \mathrm{dt}$ are determined as a function of speed. The resultant resisting torque can be calculated, knowing the geometry and mass of the rotating magnet. The figure of merit chosen [2] to compare losses in different systems is the coefficient of friction

$$
\mu=F_{D} / F_{L}=\left(2 \pi R_{\gamma}^{2} d f / d t\right) /\left(g R_{D}\right)
$$

where $R_{\gamma}$ is the rotor's radius of gyration, $R_{D}$ the mean radius at which the drag force $F_{D}$ acts, and $F_{L}$ the lift force.

The second rotor PM fabricated was spin tested at low speeds, before fiber composite banding, to determine the $\mu$ shown in Fig. 3. The losses at the largest levitation height are of the order of magnitude that would make energy storage economically possible [2].

As for the $\mu$ of previously tested small-scale, single-piece PM rings $[2,8]$, which were slightly less than half the diameter of the rotor PMs, the $\mu$ for the rotor's PM increased when the superconductors were exposed to larger magnetic fields (smaller gaps) and vice versa. However, the loss levels for the single-piece PMs were one to two orders of magnetic smaller and the slight dependence on velocity, which increases with decreased gaps size, was more discernible than in Fig. 3. As in Fig. 3, there was a clear dependence between the gap size and the zero velocity intercepts of $\mu$.

None of the rotor's PM results repudiate the existence of the dominant loss mechanisms observed in the single-piece PM testing: hysterisis in the HTS, eddy currents in the PM, and vibrations of the PMs around critical rotor speeds Singlepiece $P M$ testing $[2,8]$ showed the circumferential variations in the magnetic field, $\mathbf{B}$, is responsible for the hysterisis losses. Variations in $\mathbf{B}$ for the 2 nd rotor PM fabricated were measured at $0.006 \mathrm{~m}$ and $0.012 \mathrm{~m}$ below the entire magnet surface, and found to be less than $\pm 2.5 \%$ of $\mathrm{B}=|\mathrm{B}|$. Figure 4 shows typical results. The $\mathrm{B}$ variations for the single-piece magnets were approximately half as small.

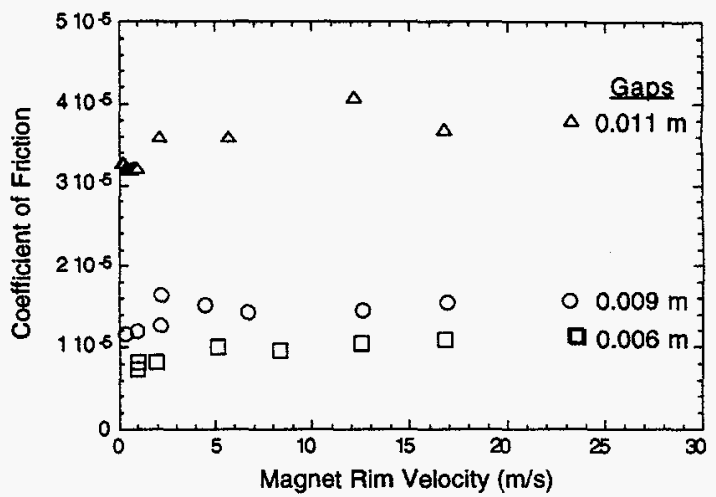

Fig. 3. Rotor B magnet's coefficient of friction is significantly smaller for larger gaps between the bottom of Rotor B magnet and the top of the superconductors, at all velocities, and only slightly dependent on velocity.

The best single-piece PMs have variations of $\pm 1 \%$.

The variations in the $B$ of the first rotor magnet fabricated were much larger, due to larger air gaps and local magnetic reversals at the seams between the magnet segments. Higher coercivity magnet material, fewer magnet seams, and greater care in assembly was used in the fabrication of the second rotor PM. Further reduction in the B variations of future rotor magnets must be achieved by improving the magnetic field uniformity of each individual magnet segment and more careful matching of the magnetic moment of adjacent segments, because the variations in B of Fig. 4 are similar in magnitude to the spatial variations measured on individual magnet segments before the magnet was assembled.

Eddy currents are suspected as responsible for much of the velocity dependence exhibited by the rotor's $\mu$ in Fig. 4 . Single-piece PM testing $[2,8]$ showed that the elimination of all conductive material within several magnet diameters, except for the PMs, resulted in substantial reductions in the dependence of $\mu$ upon velocity. The velocity dependence that remained was attributed to eddy currents induced in the PMs by field trapped in the many individual superconductors used to levitate the single-piece PM rings. Although small, if the same velocity dependence occurs at high speeds $(1000 \mathrm{~m} / \mathrm{s})$, then the increase in losses would impact the economic viability of large-scale energy storage. Some conductive material in the rotor test apparatus [2] remains in the vicinity of the PM and its elimination is planned. Future high-speed testing of single-piece and rotor PMs is planned to determine if velocity dependent losses persist at high speeds.

Rotor vibrations have been observed in all testing and the associated losses have not been included in Fig. 4; typically they are an order-of-magnitude larger than the hysterisis losses, but only occur over a narrow velocity range at the rotor critical speeds. Exceeding rotor critical speeds has not been an issue, but impassable rotor instabilities may occur at higher speeds, which will require rotor design modifications.

\section{DISCUSSION}

Comparison of the mirror-imaged magnets' repulsive pressures, calculated during rotor PM design, with those developed during HTS levitation of the rotor can serve as a measure of the HTSs' effectiveness. Levitation pressures that 


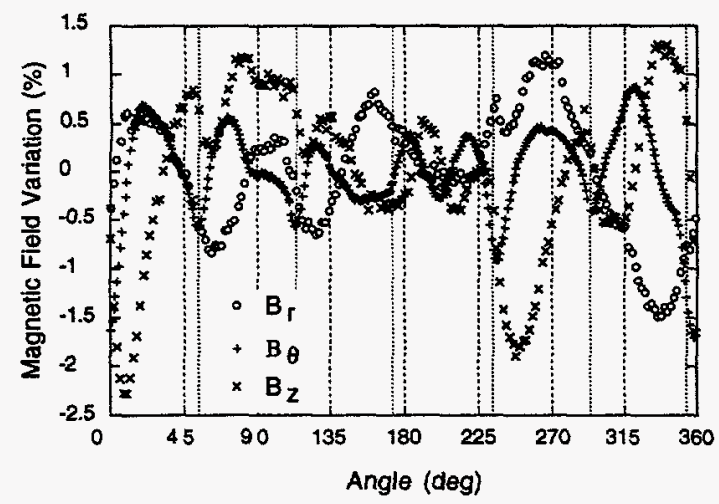

Fig. 4. Circumferential variations in the $r, \theta, z$ components of $\mathbf{B}$, at midradius and $0.006 \mathrm{~m}$ below the rotor's $P M$, are associated with segment seams (vertical lines) in the inner and outer magnet rings.

would be developed by bulk Type-1 HTSs, if they existed, would equal those of the mirror-image magnets (Meissner effect), but today's Type-2 HTSs depend primarily on pinning of the PM's magnetic flux for levitation. The melt-quenched HTS tested [9] are among the best available, but the levitation pressure developed, $8600 \mathrm{~Pa}$ at a rotor height from 0.007 to $0.009 \mathrm{~m}$, was only a small fraction, 0.12 to 0.22 , of the mirror-image magnets' pressure at a separations of twice the levitation heights. Clearly, making better HTSs will inhance HTS flywheel energy storage developement: enabling larger mass levitation and/or levitation heights with smaller losses.

Since HTS hysterisis is mainly responsible for the rotor magnet's $\mu$ in Fig. 3, and is activated by circumferential inhomogeneity of the PM's magnetic field, a figure of merit, $\lambda$, is proposed for comparing the effectiveness of different PMs in minimizing hysteretic losses in an HTS bearing:

$$
\lambda=\frac{\mathrm{e}_{\ell}}{\mathrm{e}_{\mathrm{p}}} \sim \operatorname{average}\left[\sum_{\mathrm{n}}\left(\Delta \mathrm{B}_{\mathrm{n}}^{3} / \mathrm{J}_{\mathrm{c}}\right) /\left(\mathrm{B}_{\mathrm{t}}^{2} \mathrm{~h}\right)\right]_{\mathrm{r}},
$$

where $e_{\ell}$ is the energy loss/(unit surface area) of a hard (Type 2) HTS, whose flux flow and hysterisis losses are determined using the critical-state model [2], [10] and critical current, $\mathrm{J}_{\mathrm{C}}$. Also, $e_{p}$ is a measure of the PM's potential energy/(unit surface area) over a Type-1 HTS (Meissner Effect). In the evaluation of $e_{p}$, the tangential field, $B_{t}$, is interpreted as $B$ at the Type-1 HTS surface, where flux does not penetrate, and the denominator of (2) as proportional to the magnetic pressure [11] times the PM's distance, $h$, above the surface. In $e_{\ell}, \Delta B_{n}$ represents the change in $B_{t}$, at one point on the HTSs' surface, during the nth half cycle of the magnetic field fluctuations created during one PM revolution. Summation is over all $\mathrm{n}$, and averaging is over all radii, $\mathrm{r}$.

Certainly, $\lambda$ is only an approximation to the loss factor for real HTSs, because, in particular, flux penetrates the superconductor surface [4], [10]. In any case, a priori knowledge of B at the surface of the HTS can not be predicted, nor can the circumferential variations in the PM's field. The suggested method of calculating $\lambda$ is to measure the field of the PM isolated from other magnetic bodies: choose a distance $d$ below the bottom of the PM and a radius $r=r_{i}$, then make enough measurements of $\mathrm{B}$ to characterize the circumferential field variations. Determine the mean value, $B_{\mathfrak{i}}$, of all the $B$ at $r=r_{i}$; calculate the ratios and sum in (2), using $h=d$ and $B_{t}=$ $B_{i}$; repeat the measurements at other $r$; and average the $\lambda_{i}$ at different $r_{i}$, until the average, $\lambda$, remains nearly unchanged.

Judgment in making the calculations is required, particularly choosing $\Delta \mathrm{B}_{\mathrm{n}}$. (A programable algorithm has been developed [12] for future use.) Also, relatively small variations in $\Delta B_{n}$ are insignificant, because $\Delta B_{n}$ is cubed and then summed in (2). In addition, $h$ should be chosen as the expected levitation heights. The $r$ can be limited to where PM's field has significant interaction with the HTSs.

Using the above procedure a modified $\lambda$, called $\phi$, was calculated by hand for 40 of the small single-piece magnets, and both the first (A) and the improved second version (B) of the rotor's magnet. The single piece magnets were all similar to the one used in previous loss-coefficient testing [2], [8], and $\phi$ is the main parameter used in selecting test magnets. The $J_{c}$ and $h$ were not included in the loss factor $\phi$, because the granular $\mathrm{J}_{\mathrm{cg}}$ of the HTS were not measured directly and all B were measured $\mathrm{h}=0.006 \mathrm{~m}$ for all magnets. Based on levitation force measurements of each HTS used, the $J_{\mathrm{cg}}$ for all the superconductors are within a factor of 3 of each other.

The loss factor $\phi$ for the $K$ magnets varied between a high of 1.2 and a low of 0.006 , for the test magnet $(K)$ used to report very low $\mu$ [2], [8]. Usually, only a few sets of the measurements at different $r_{i}$ were necessary to converge to a $\phi$ value accurate to within $\pm 10 \%$. Rotor magnet $A$ was found to have $a \phi$ of 16 and magnet $B$ a $\phi$ of 0.7 .

The hysteretic components of $\mu$ (zero velocity value) for the PMs K, A, and B were $7 \times 10^{-7}, 4 \times 10^{-4}$, and $3 \times 10^{-5}$ at levitation heights between 0.009 and $0.010 \mathrm{~m}$. Clearly, the loss factors, $f$, are approximately (first order) in the same ratios as the hysteretic coefficient of friction $\mu$.

\section{ACKNOWLEDGMENTS}

The efforts of A. Wantroba, R. Smith, and C. Macione at ANL are appreciated.

\section{REFERENCES}

[1] R. Abboud, J. Hull, K. Uherka, and T. Mulcahy, "Flywheel energy storage using superconducting magnetic bearings," Proc. Am. Power Conf., Chicago, vol. 56-II, pp. 1356-1361, April 1994.

[2] J. R. Hull, T. M. Mulcahy, K. L. Uherka, R. A. Erck, and R. A. Abboud, "Flywheel energy storage using superconducting magnetic bearings," Appl. Supercond., vol. 2, pp. 449-455, 1994.

[3] H. J. Borneman et al., "Low friction in a flywheel system with passive superconducting bearings," Appl. Supercond. vol. 2, pp. 439, 1994.

[4] F. C. Moon, "Magnetic forces in high-Tc superconducting bearings," Applied Electromagnetics in Materials," vol. 1, pp. 29-35, 1990.

[5] Genta, G., Kinetic Energy Storage: Theory and Practice of Advanced Flywheel Systems, Butterworth Lid., 1985.

[6] Lekhnitski, S. G., Anisotropic Plates, Gordon and Breach Science Publishers, New York, 1968.

[7]. C. W. Gabrys and C. E. Bakis, "Fabrication of thick filament wound carbon epoxy rings using in-situ curing, "Proc. Am. Soc. Composites, 7th Annual Technical Conf, Lancaster. PA, pp. 1090-94, 1994.

[8] J. R. Hull, T. M. Mulcahy, K. L. Uherka, and R. G. Abboud, "Low rotational drag in high-temperature superconductors." IEEE Trans. Appl. Supercond., May, 1994, in press.

[9] D. Shi, et al., "Processing strongly pinned, large domain $\mathrm{YBa} 2 \mathrm{CuOx}$ for magnetic levitation," IEEE Trans. Appl. Supercond. 1994, in press.

[10] L. C. Davis, "Lateral restoring force on a magnet levitated above a superconductor," J. Appl. Phy. Vol. 67(2), pp. 2631-2636, 1990.

[11] F. C. Moon, Superconducting Levitation, John Wiley, 1994, pp. 35, 54.

[12] T. M. Mulcahy and J. R. Hull, "A hard superconductor model for cyclic hystersis losses," unpublished. 